\title{
Effects of the slow cooling during cryopreservation on the survival and morphology of Taiwan shoveljaw carp (Varicorhinus barbatulus) spermatozoa
}

\author{
Sujune Tsai ${ }^{3}$, Emma Spikings ${ }^{2}$, Ching-Chiang Hwang ${ }^{2}$ and Chiashin Lin ${ }^{1, \mathrm{a}}$ \\ ${ }^{1}$ National museum of marine biology \& Aquarium, 2 Houwan Road, Checheng, Pingtung 944, Taiwan \\ 2 LIRANS Institute of research in the applied natural sciences, University of Bedfordshire, 250 Butterfield, Great Marlings, Luton, \\ Bedfordshire LU2 8DL, UK \\ 3 Department of biotechnology, Mingdao University, 369 Wenhua Road, Peetow, Chang Hua 52345, Taiwan
}

Received 3 July 2009; Accepted 5 November 2009

\begin{abstract}
Over the past decades, pollution, overfishing, and habitat degradation have driven the population size of Taiwan shoveljaw carp down markedly in Taiwan. Cryopreservation is a useful tool which could be used to maintain genetic resources to protect and preserve this endemic species. Four cryoprotectants [dimethyl sulphoxide (DMSO), dimethylacetamide (DMA), glycerol and methanol] and six freezing rates $\left(0.5,1,2,4,8,16^{\circ} \mathrm{C} \mathrm{min}^{-1}\right)$ were tested in order to develop an optimal controlled slow-freezing protocol for Taiwan shoveljaw carp spermatozoa. Samples were subsequently examined under the scanning electron microscope to reveal whether cryopreservation had affected their ultrastructural morphology. The highest survival rate $(50.1 \pm 2.0 \%)$ was observed with a freezing rate of $8{ }^{\circ} \mathrm{C} \mathrm{min}{ }^{-1}$ in $1 \mathrm{M}$ DMSO, using SYBR-14 + PI staining. Fertility and hatching rate results using frozen-thawed spermatozoa $(90.2 \pm 2.2 \%$ and $22.3 \pm 2.5 \%$, respectively) were not significantly different from results with fresh spermatozoa. After cryopreservation, $21.0 \pm 1.6 \%$ of frozen-thawed spermatozoa had mid-piece swelling and rupture of the head. Cryopreservation might, therefore, slightly affect Taiwan shoveljaw carp spermatozoa in terms of morphological change. However, these alterations could be compensated by using large enough numbers of normally functioning frozen-thawed spermatozoa to achieve a standard equal to fresh spermatozoa. This is the first report of successful cryopreservation of Taiwan shoveljaw carp spermatozoa using a controlled slow-cooling method.
\end{abstract}

Key words: Cryopreservation / Scanning electron microscope / Freezing rate / Fertilisation / Taiwan shoveljaw carp / Cyprinidae

\section{Introduction}

The Taiwan shoveljaw carp Varicorhinus barbatulus, a small freshwater fish endemic to Taiwan, was first described by Oshima (1920). This species is also distributed in China. The Taiwan shoveljaw carp can be found in the fast-running streams located in a mountainous area of Taiwan, at an altitude ranging from 520-1230 m. Over recent decades, pollution, overfishing, and habitat degradation have driven the population size of the species down markedly in Taiwan. It is therefore high time to consider the conservation of the species.

There is a consensus that environmental preservation is the best procedure for the maintenance of endangered species, but that long-term genebanking methods are required to preserve species. Cryopreservation of spermatozoa is a reliable

\footnotetext{
a Corresponding author: chiahsin@nmmba.gov. tw
}

procedure for the maintenance of fish species because of the relative ease of freezing and storage. The advances in artificial propagation may facilitate the applicability of the spermatozoa cryopreservation in repository genebanks. Techniques of spermatozoa management have been established in some freshwater (Bokor et al. 2007; Babiak et al. 1997) and marine (Van der Straten et al. 2006; Suquet et al. 2000) fish species. Generally, higher survival and fertilisation capacity were obtained in frozen-thawed spermatozoa of marine fish species compared with freshwater species (Drokin 1993; Gwo 2000).

Many reports have been published on the cryopreservation of spermatozoa of freshwater fish, but there is no information on cryopreservation of Taiwan shoveljaw carp spermatozoa. The present study set out to develop a protocol for spermatozoa cryopreservation in Taiwan shoveljaw carp in order to build a genebank for this species. Spermatozoa ultrastructure and rates of fertilisation and hatching obtained with cryopreserved 
spermatozoa were also examined. The protocols established in this study are expected to assist preservation of germplasm resources in $V$. barbatulus.

\section{Materials and methods}

\subsection{Collection of spermatozoa and oocytes}

Taiwan shoveljaw carp were obtained from the Marine station, National Museum of Marine Biology and Aquarium, Taiwan. The fish were maintained in 1 ton tanks with water and a cooling circulating system at $16{ }^{\circ} \mathrm{C}$, under a controlled day-night cycle of $14 \mathrm{~h}$ light/10 h dark. Three males and three females were used for each experiment and its repeats (9-9 individuals in total). Semen was collected by applying gentle pressure to the abdomen of mature male Taiwan shoveljaw carp of 150-200 g. Semen was then transferred into $15 \mathrm{ml}$ centrifuge tubes and kept on crushed ice until the following part of the experiment. To maintain spermatozoa quality, any contaminating faeces, urine and blood were removed by discarding the first part of the semen during collection. The collection of oocytes was carried out by a hormone-induced spawning method using two injected doses of carp pituitary. The first injection, of $0.01 \mathrm{~g}$ per $100 \mathrm{~g}$ fish weight, was made at $6 \mathrm{pm}$ in the afternoon; the second injection, of $0.015 \mathrm{~g}$ per $100 \mathrm{~g}$ fish weight, was made at $12 \mathrm{pm}$ midnight. Approximately 8 hours after the second injection, eggs were obtained by hand striping of the female abdomen (these procedures have been approved by animal ethics committee of National Museum of Marine Biology \& Aquarium).

\subsection{Toxicity of cryoprotectants}

Fish saline extender $(136.7 \mathrm{mM} \mathrm{NaCl}, 6.7 \mathrm{mM} \mathrm{KCl}$, $83.3 \mathrm{mM}$ D-glucose; $355 \mathrm{mOsmol} \mathrm{kg}^{-1}$ ) (Chen et al. 1992) and cryoprotectants were first precooled to $5{ }^{\circ} \mathrm{C}$. Semen was then diluted 1:10 in fish saline extender. The toxicity test consisted of exposing the diluted semen for $15 \mathrm{~min}$ to the four penetrating cryoprotectants: dimethyul sulfoxide (DMSO), dimethylacetamide (DMA), glycerol and methanol (Sigma, St. Louis MO, USA) at final concentrations of $0,1,2,3 \mathrm{M}$. To obtain the desired final concentrations, $50 \mu \mathrm{l}$ cryoprotectant solution, prepared at double concentration using fish saline extender, were added to microtubes containing $50 \mu \mathrm{l}$ diluted semen. After cryoprotectants had equilibrated for $15 \mathrm{~min}$, the No Observed Effect Concentration (NOEC) the highest concentration found to produce no statistically significant difference in viability compared with the control was determined for each cryoprotectant using a SYBR-14 + propidium iodide (PI) staining (LIVE/DEAD assay kit, Invitrogen, USA).

\subsection{Freezing and thawing}

Diluted semen (1:10 in fish saline extender) was mixed with 1M DMSO, DMA and glycerol, and 2M methanol separately in $1.5 \mathrm{ml}$ Eppendorf tubes, and equilibrated for $15 \mathrm{~min}$ at $5{ }^{\circ} \mathrm{C}$. During the equilibration time, spermatozoa were drawn into $0.25 \mathrm{ml}$ plastic straws (IMV, France), which were then sealed at the open end with sealing powder. Freezing was conducted using a programmable freezer (CryoMed Freezer 7456, Thermo, USA) and the following freezing program: $2{ }^{\circ} \mathrm{C} \min ^{-1}$ to seeding temperature $\left(-6{ }^{\circ} \mathrm{C}\right.$ for DMSO, DMA and glycerol and $-7.5^{\circ} \mathrm{C}$ for methanol), held for $10 \mathrm{~min}, 0.5,1$, $2,4,8,16^{\circ} \mathrm{C} \min ^{-1}$ to $-40{ }^{\circ} \mathrm{C}, 10^{\circ} \mathrm{C} \mathrm{min}^{-1}$ to $-80{ }^{\circ} \mathrm{C}$, held for $10 \mathrm{~min}$. At the ice-seeding temperature, ice-seeding took place by touching the straws with forceps which had previously been held at $-196{ }^{\circ} \mathrm{C}$. Ice-seeding was successful when the formation of ice crystals was observed within the clear medium inside the straw. At the end of the program, at $-80^{\circ} \mathrm{C}$, the straws were removed and immediately plunged into liquid nitrogen for at least $10 \mathrm{~min}$. For the thawing procedure, each straw was placed in a water bath at $30{ }^{\circ} \mathrm{C}$ until the crystals dissipated.

\subsection{Viability assessment}

The viability assessment was carried out using SYBR-14 and PI staining. The dyes were freshly prepared before use. Firstly, SYBR-14 $1 \mathrm{mM}$ was diluted 500 fold and PI $2.4 \mathrm{mM}$ was diluted 10 fold in fish saline solution to produce working solutions of $2 \mu \mathrm{M}$ and $240 \mu \mathrm{M}$, respectively. Then, $1 \mu \mathrm{l}$ SYBR-14 working solution and $1 \mu \mathrm{l}$ PI working solution were added directly to $20 \mu \mathrm{l}$ diluted spermatozoa solution (1: 1000 in fish saline extender). The final PI concentration was $12 \mu \mathrm{M}$ and the SYBR-14 concentration was $0.1 \mu \mathrm{M}$. The spermatozoa were stained in the dark for 3-5 min. Evaluation of viability was then conducted by fluorescent microscopy (magnification: $100 \times$, Axioskop2 plus, ZEISS, Germany) with a haemocytometer. When the stain combination was excited at $488 \mathrm{~nm}$, spermatozoa fluorescing bright green were classified as viable, while those stained red were classified as damaged. The SYBR-14 + PI staining for spermatozoa was calculated as follows: Viability $(\%)=$ number of green cells $/$ (green cells + red cells) $\times 100 \%$.

\subsection{Fertilisation trial}

Approximately 4000 eggs from each female were inseminated with $2 \mathrm{ml}$ of fresh or frozen-thawed spermatozoa solution at ratios of $1: 1 \times 10^{6}$ and 1: $2 \times 10^{6}$, respectively $(2 \mathrm{ml}$ semen solution contains $0.2 \mathrm{ml}$ pure semen; spermatozoa concentration of Taiwan shoveljaw carp is $2 \times 10^{10} \mathrm{ml}^{-1}$ ). These ratios are reported to achieve the highest fertilisation rates with Cyprinid semen (Lahnsteiner et al. 2003). The activation of spermatozoa was carried out by adding $20 \mathrm{ml}$ fresh water $\left(16{ }^{\circ} \mathrm{C}\right)$ after the mixing of semen and eggs. The eggs were then placed into a $2 \mathrm{~L}$ upwelling unit with sufficient flow to gently tumble the developing embryos. The flow rate was adjusted to lift about 50 percent of their static depth $\left(20 \mathrm{ml} \mathrm{s}^{-1}\right)$. The water temperature in the hatching system was maintained at $16{ }^{\circ} \mathrm{C}$ using a temperature-controlled bath equipped with a cooler. Removal of dead eggs was carried out from time to time, as necessary. After $30 \mathrm{~min}$, the number of fertilised eggs that had reached the cleavage stage was recorded and used to calculate fertilisation rate. The fertilised eggs began to hatch 
at $116 \mathrm{~h}$ and the hatching rates were also recorded. The fertilisation and hatching rates were calculated using the formulae below:

$$
\begin{aligned}
\text { Fertilisation rate }(\%)= & \text { number of cleavage stage embryos } / \\
& \text { number of total eggs } \times 100 \% \\
\text { Hatching rate }(\%)= & \text { number of hatched fry } / \\
& \text { number of fertilised eggs } \times 100 \%
\end{aligned}
$$

\subsection{Scanning electron microscopy}

Scanning electron microscopy was used to determine ultrastructural changes following cryopreservation. Fresh and frozen-thawed spermatozoa solutions of $400 \mu 1$ were pre-fixed for $2 \mathrm{~h}$ in $4 \%$ formaldehyde diluted in distilled water and postfixed with $2 \%$ osmium tetroxide solution for $1 \mathrm{~h}$ at $4{ }^{\circ} \mathrm{C}$. After fixing, the samples were washed in double distilled water and dehydrated through a 6 ethanol series of 35\%, 50\%, 70\%, 90\%, $95 \%$ and $100 \%$. A critical point dryer (HCP-2, Hitachi, Japan) and SEM Ion Sputter (E1010, Hitachi, Japan) were used to dry and coat the samples with gold-platinum. Samples were examined using a Scanning Electron Microscope (S-3500N, Hitachi, Japan). In each experimental repeat, means of the spermatozoa parameters and SE were obtained from counts on 3 replicates.

\subsection{Statistical analysis}

For all experiments, three replicates were used for each treatment and experiments were repeated at least three times. The one-sample Kolmogorov-Smirnov test was performed to determine whether the data were normally distributed. Statistical data were then analysed using one-way analysis of variance with Tukey's post hoc tests (SPSS Version 12.0, USA) to test for significant differences between the mean values from experimental treatments, and to determine which groups specifically differed. A Student's $t$-test was used to determine the difference between fresh and frozen-thawed spermatozoa. The results of the study are presented as mean \pm standard error.

\section{Results}

\subsection{Toxicity of cryoprotectants}

The NOECs for methanol, DMA, DMSO and glycerol for Taiwan shoveljaw carp spermatozoa using SYBR-14 + PI staining are given in Table 1. Methanol was the least toxic cryoprotectant to Taiwan shoveljaw carp spermatozoa, and there were no differences between toxicity of DMA, DMSO and glycerol. The survival rates assessed using SYBR-14 + PI staining after exposure to NOEC concentrations of cryoprotectants (1M DMSO, DMA and glycerol and 2M methanol) for $15 \mathrm{~min}$ were $87.2 \pm 0.9 \%, 83.8 \pm 2.0 \%, 85.4 \pm 1.5 \%$ and $83.2 \pm 1.7 \%$, respectively.

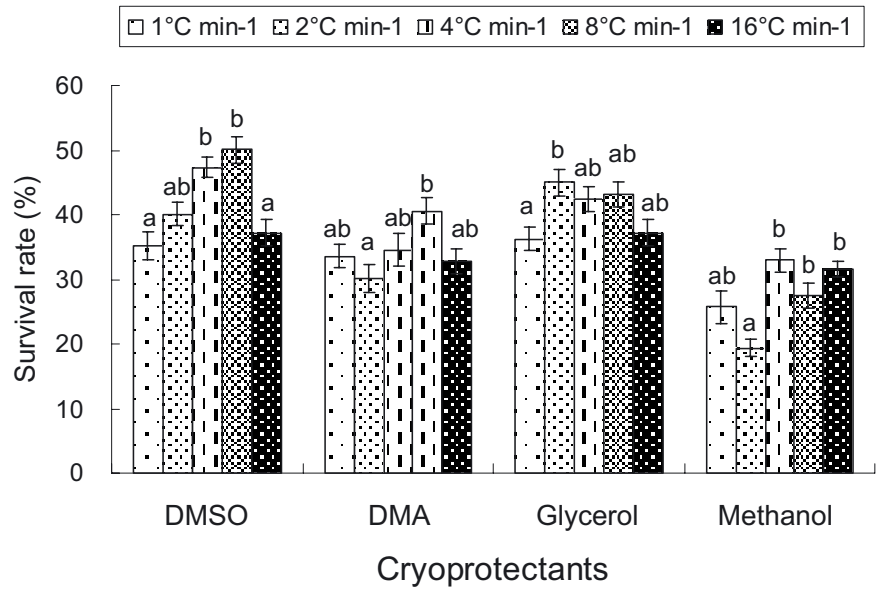

Fig. 1. Effect of post ice-seeding freezing rate $\left(1,2,4,8,16^{\circ} \mathrm{C} \mathrm{min}^{-1}\right)$ on survival of Taiwan shoveljaw carp spermatozoa in $1 \mathrm{M}$ DMSO, DMA and glycerol and 2M methanol assessed by SYBR-14+PI using a controlled slow-freezing method. Error bars represent standard error of the mean. Different letters represent significant difference between freezing rates for spermatozoa treated with the same cryoprotectant $(p<0.05)$.

\subsection{Freezing and thawing}

The effect of different post ice-seeding freezing rates (ranging from $1-16{ }^{\circ} \mathrm{C} \mathrm{min}{ }^{-1}$ ) are shown in Figure 1 and Table 2. The highest survival rates were obtained with a freezing rate of $8{ }^{\circ} \mathrm{C} \mathrm{min}-1$ and with a cryoprotectant solution of $1 \mathrm{M}$ DMSO. The survival rate after freezing was $50.1 \pm 2.0 \%$. Moderate freezing rates are shown to be more beneficial than faster or slower rates when cryopreserving with DMSO. Survival rates with methanol were generally lower than with the other three cryoprotectants, and spermatozoa motility was low at all tested freezing rates except $16^{\circ} \mathrm{C} \mathrm{min}^{-1}$.

In the light of the results from these studies, the following optimal protocol was adopted for the fertilisation trial and scanning electron microscopic experiment using $1 \mathrm{M}$ DMSO: cooling at $2^{\circ} \mathrm{C} \mathrm{min}{ }^{-1}$ to $-6^{\circ} \mathrm{C}$ seeding temperature, held for $10 \mathrm{~min}, 8{ }^{\circ} \mathrm{C} \mathrm{min}{ }^{-1}$ to $-40{ }^{\circ} \mathrm{C}, 10{ }^{\circ} \mathrm{C} \min ^{-1}$ to $-80{ }^{\circ} \mathrm{C}$, held for $10 \mathrm{~min}$. The straws were then plunged into liquid nitrogen

\subsection{Fertilisation trial}

The results of fertility and hatching rate using fresh and frozen-thawed spermatozoa are shown (Fig. 1). Fertilisation and hatching rates were significantly lower when using an egg to frozen-thawed spermatozoa ratio of $1: 1 \times 10^{6}(p<0.05)$. An increased ratio of $1: 2 \times 10^{6}$ improved the fertilisation and hatching rates, which were then not significantly different from those achieved using fresh spermatozoa $(p>0.05)$. The fertilisation and hatching rates obtained with fresh and frozenthawed spermatozoa are shown in Table 2.

\subsection{Scanning electron microscopy}

The ultrastructural observations made on Taiwan shoveljaw carp spermatozoa after optimal freezing procedure are 


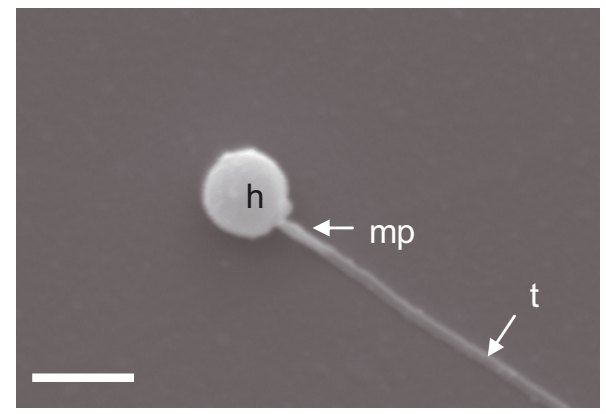

a

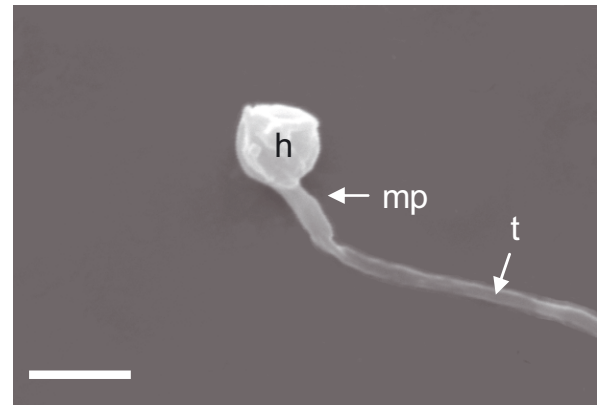

b

Fig. 2. Ultrastructure of fresh and frozen-thawed Taiwan shoveljaw carp spermatozoa using scanning electron microscopy; (a) fresh spermatozoon, (b) frozen-thawed spermatozoon with a low degree of swelling at the mid-piece. $\mathrm{h}=$ spermatozoon head; mp = spermatozoon mid-piece; $\mathrm{t}=$ spermatozoon tail. Scale bar $=2 \mu \mathrm{m}$.

Table 1. No observed effect concentrations (NOEC) of cryoprotectants obtained from SYBR-14+PI staining on Taiwan shoveljaw carp spermatozoa. The highest concentration of cryoprotectants used in the experiment was $5 \mathrm{M}$ for $10 \mathrm{~min}$.

\begin{tabular}{cc}
\hline Cryoprotectants & NOEC \\
\hline DMSO & $1 \mathrm{M}$ \\
DMA & $1 \mathrm{M}$ \\
Glycerol & $1 \mathrm{M}$ \\
Methanol & $2 \mathrm{M}$ \\
\hline
\end{tabular}

Table 2. Fertilisation and hatching rates of fresh and frozen-thawed spermatozoa (spz).

\begin{tabular}{lccc}
\hline $\begin{array}{l}\text { Spermatozoa } \\
\text { source }\end{array}$ & $\begin{array}{c}\text { Egg to spermatozoa } \\
\text { ratio }\end{array}$ & $\begin{array}{c}\text { Fertilisation } \\
\text { on rates }(\%)\end{array}$ & $\begin{array}{c}\text { Hatching } \\
\text { rates }(\%)\end{array}$ \\
\hline Fresh spz & $1: 1 \times 10^{6}$ & $96.2 \pm 1.9^{\mathrm{a}}$ & $32.4 \pm 2.1^{a}$ \\
Post-thawed spz & $1: 1 \times 10^{6}$ & $79.4 \pm 2.3^{\mathrm{b}}$ & $20.3 \pm 1.8^{\mathrm{b}}$ \\
Post-thawed spz & $1: 2 \times 10^{6}$ & $90.2 \pm 2.2^{\mathrm{ab}}$ & $22.3 \pm 2.5^{\mathrm{ab}}$ \\
\hline
\end{tabular}

Different letters represent significant difference between spermatozoa samples $(p<0.05)$.

shown (Fig. 2). The main structures comprise the spermatozoa head, midpiece and flagellum. The round head of fresh spermatozoa had a diameter of $1.8 \pm 0.02 \mu \mathrm{m}$ and the flagellum had a length of $43.4 \pm 1.3 \mu \mathrm{m}$ (Fig. 2a). After cryopreservation, $21.0 \pm 1.6 \%$ of frozen-thawed spermatozoa exhibited morphological changes such as mid-piece swelling and rupture of the head (Fig. 2b). This was significantly higher than in fresh spermatozoa $(3.3 \pm 0.6 \%)$.

\section{Discussion}

Cryoprotectants play an important role in cryopreservation. They provide protection against the harmful effects of long term storage in liquid nitrogen (Muchlisin 2005). However, cryoprotectants can be lethal to spermatozoa. Therefore, studies on the toxicity of cryoprotectants are very important. In the study, we found that when Taiwan shoveljaw carp spermatozoa were mixed with $1 \mathrm{M}$ DMSO, DMA and glycerol and $2 \mathrm{M}$ methanol for 15 min at $5^{\circ} \mathrm{C}$, there was no significant reduction in the survival rates compared with fresh spermatozoa. Therefore, these concentrations were used in the subsequent freezing experiment, and any alteration of survival rate after cryopreservation could be wholly attributed to the freezing and thawing injury.

When liquid water is converted into ice (at approximately -5 to $-50{ }^{\circ} \mathrm{C}$ ), cells are subjected to a series of drastic changes in their chemical and physical environment (Watson 2000). The capacity to survive freezing in this critical temperature depends upon the cryoprotectant and optimum freezing rate (Andrabi 2007). Our results regarding survival rate and motility of Taiwan shoveljaw carp spermatozoa after cryopreservation demonstrated that DMSO was the best cryoprotectant in the freezing experiments. These results agree with several previous findings where DMSO has been used successfully with spermatozoa of many fish species (Muchlisin 2005; Horváth et al. 2003; Melo and Godinho 2006; Ji et al. 2008; Tian et al. 2008). Although methanol has been used successfully as a cryoprotectant for the cryopreservation of spermatozoa of channel catfish (Christensen and Tiersch 2005), bitterling (Ohta et al. 2001) and bagrid catfish (Muchlisin and Muhammadar 2002), in our study cryopreservation with methanol appeared to be less efficient than DMSO, DMA and glycerol in terms of survival rate and motility. With the controlled slowfreezing method, the freezing rate is a key factor that needs to be considered. Ideal freezing rates for fish spermatozoa vary according to species. Freezing catfish, zebrafish and medaka spermatozoa requires freezing rates of -3 to $-12{ }^{\circ} \mathrm{C} \mathrm{min}{ }^{-1}$ (Christensen and Tiersch 2005; Viveiros et al. 2001; Mongkonpunya et al. 1995; Tiersch and Yang 2009), which are similar to the optimal freezing rate of $8{ }^{\circ} \mathrm{C} \mathrm{min}^{-1}$ obtained in our results. On the other hand, faster freezing rates (ranging from $18-30{ }^{\circ} \mathrm{C} \mathrm{min}^{-1}$ ) result in better survival of spotted halibut, neotropical genera and Xiphophorus spermatozoa in cryopreservation (Melo and Godinho 2006; Tian et al. 2008; Tiersch and Yang 2009).

Freezing and thawing of spermatozoa can impair cellular functions, therefore reducing fertility (Hammerstedt et al. 1990). New approaches to functionally assess thawed spermatozoa using fluorescent probes have been developed and can provide information regarding the capacity of spermatozoa to 
tolerate freezing and thawing. These approaches have been successfully used in mammals (Garner and Johnson 1995) and fish species (Flajšhans et al. 2004). Dual-staining techniques that utilize dye make it possible to stain cells with damaged plasma membranes. Fluorochrome SYBR 14 is able to penetrate the spermatozoon head and stain the nucleic acids of viable (membrane-intact) cells. Fluorochrome PI can be used to identify non-viable cells because it can only penetrate damaged nuclear membranes and then stain nucleic acid by intercalating between the base pairs (Garner et al. 1994). In the present study, the fluorescent dyes (SYBR 14 and PI) could be used to assess spermatozoa function of the Taiwan shoveljaw carp as they indicated plasma membrane damage and mitochondrial membrane potential.

The most reliable method of assessing spermatozoa quality has been to measure fertilisation or hatching rate. In general, spermatozoa motility in carp species can be achieved by reducing osmolality (Boryshpolets et al. 2009; Perchec-Poupard et al. 1997). Although the cryopreservation procedure and DMSO exposure might activate spermatozoa motility of Cyprinus carpio (Perchec Poupard et al. 1997; Boryshpolets et al. 2009), the spermatozoa of Taiwan shoveljaw carp remained immotile after mixing with fish saline extender and cryoprotectants. This result was in agreement with that found in another species, Varicorhinus macrolepis (Ji et al. 2008). In the present study, fertilisation and hatching rates using cryopreserved spermatozoa were significantly lower than with fresh spermatozoa when using an egg to frozen-thawed spermatozoa ratio of $1: 1 \times 10^{6}$. However, increasing the volume of frozen-thawed spermatozoa to give a ratio of $1: 2 \times 10^{6} \mathrm{im}-$ proved the fertilisation and hatching rate, which were then not significantly different from results with fresh spermatozoa. Frozen-thawed spermatozoa are more fragile than fresh spermatozoa because they have suffered the effects of freezing (Tian et al. 2008). Therefore, a higher density of frozen-thawed spermatozoa would be needed than fresh spermatozoa to compensate for this and allow successful fertilisation results (Chao and Liao 2001). Although our hatching system has been able to obtain high hatching rates with tilapia and common carp (over 90\%), the hatching rate of Taiwan shoveljaw carp has been relatively low. There is a need for an improved hatching system to give a high and reproducible hatching rate.

The structure of the Taiwan shoveljaw carp spermatozoa is similar to that in other teleost species (Emaljanova and Makeeva 1985; Psenicka et al. 2006). However, the head sizes of the teleost fish spermatozoa are relatively larger $(2-4 \mu \mathrm{m})$ than those of Taiwan shoveljaw carp (Linhart and Benesovsky 1991). During the process of cryopreservation, there are many factors that affect success, such as cryoprotectant toxicity, chilling injury, solution effect, volume effect and osmotic effect (Lin et al. 2009). In our ultrastuctural investigation, $21 \pm 1.6 \%$ of frozen-thawed spermatozoa had slight midpiece swelling and head rupture. Similar results were found in frozen-thawed spermatozoa of red seabream (Liu et al. 2007), grayling (Lahnsteiner et al. 1992) and ocean pout (Yao et al. 2000). As the mid-piece contains mitochondria, cryopreservation might affect mitochondrial energy metabolism and then reduce fertilisation capacity of frozen-thawed spermatozoa and subsequent hatching rate (Liu et al. 2007). These results are consistent with the result we obtained in the fertilisation and hatching trial, with the fresh spermatozoa giving significantly higher fertilisation and hatching rate than frozenthawed spermatozoa when using an egg to frozen-thawed spermatozoa ratio of $1: 1 \times 10^{6}$. However, an increased ratio of 1 : $2 \times 10^{6}$ improved the fertilisation and hatching rate, which were then not significantly different from rates obtained with fresh spermatozoa. This might be because those frozen-thawed spermatozoa that survived had an equivalent fertilisation capacity to fresh spermatozoa. It is also possible that there was simply a sufficient number of good quality spermatozoa within the frozen-thawed sample to allow fertilisation to take place (Liu et al. 2007).

In conclusion, Taiwan shoveljaw carp spermatozoa was successfully cryopreserved for the first time in this study. Techniques using fluorescent dyes can be used to assess postthaw spermatozoa quality of Taiwan shoveljaw carp. Although some spermatozoa had slight morphological abnormalities after cryopreservation, the fertilisation and hatching rates obtained with frozen-thawed spermatozoa were not significantly different from those obtained with fresh spermatozoa. However, it is still important that further studies be carried out to assess long-term growth and development of fish produced with frozen-thawed spermatozoa.

\section{References}

Andrabi S.M.H., 2007, Fundamental principles of cryopreservation of Bos taurus and Bos indicus bull spermatozoa. Ind. J. Agric. Biol. 2, 367-369.

Babiak I., Glogowsk J., Brzuska E., Szumiec J., Adamek J., 1997, Cryopreservation of sperm of common carp Cyprinus carpio. Aquac. Res. 28, 567-571.

Bokor Z., Müller T., Bercsényi M., Horváth L., Urbányi B., Horváth A., 2007, Cryopreservation of sperm of two European percid species, the pikeperch (Sander lucioperca) and the Volga pikeperch (S. volgensis). Acta. Biol. Hung. 58, 199-20.

Boryshpolets S., Dzyuba B., Rodina M., Li P., Hulak M., Gela D., Linhart O., 2009 Freeze-thawing as the factor of spontaneous activation of spermatozoa motility in common carp (Cyprinus carpio L.). Cryobiology 59.

Chao N.H., Liao I.C., 2001, Cryopreservation of finfish and shellfish gametes and embryos. Aquaculture 197, 161-189.

Chen S.L., Liu X.T., Lu D.C., Zhang L.Z., Fu C.J., Fang J.P., 1992, Cryopreservation of spermatozoa of silver carp, common carp, blunt snout bream and grass carp. Acta Zool. Sin. 38, 413-424.

Christensen J.M., Tiersch T.R., 2005, Cryopreservation of channel catfish sperm: effects of cryoprotectant exposure time, cooling rate, thawing conditions, and male-to-male variation. Theriogenology 63, 2103-2112.

Drokin S.I., 1993, Phospholipid distribution and fatty acid composition of phosphatidylcholine and phosphatidylethanolamine in sperm of some freshwater and marine species of fish. Aquat. Living Resour. 6, 49-56.

Emaljanova N.G, Makeeva A.P., 1985, Ultrastructure of spermatozoids of some cyprinid fishes (Cyprinidae). J. Appl. Ichthyol. 25, 137-144.

Flajshans M., Cosson J., Rodina M., Linhart O., 2004, The application of image cytometry to viability assessment in dual fluorescence-stained fish spermatozoa. Cell Biol. Int. 28, 955-959. 
Garner D.L, Johnson L.A, Yue S.Y, Roth B.L, Haugland R.P., 1994, Dual staining assessment of bovine sperm viability using SYBR 14 and propidium iodide. J. Androl. 15, 620-629.

Garner D.L., Johnson L.A., 1995, Viability assessment of mammalian sperm using SYBR 14 and propidium iodide. Biol. Reprod. 53, 276-284.

Guest W.C., Avault J.W., Roussel J.D., 1976, Preservation of channel catfish sperm. Trans. Am. Fish. Soc. 3, 469-474.

Gwo J.C., 2000, Cryopreservation of aquatic invertebrate semen: A review. Aquac. Res. 31, 259-271.

Hammerstedt R.H., Graham J.K., Nolan J., 1990, Cryopreservation of mammalian sperm: what we ask them to survive. J. Androl. 11, $73-88$.

Horváth Á., Miskolczi E., Urbányi B., 2003, Cryopreservation of common carp sperm. Aquat. Living Resour. 16, 457-460.

Ji X.S., Zhao Y., Chen S.L., Jiang Y.L., Wang H., Song J.Y., Ding L., Chen H.J., 2008, Successful fertilisation of Varicorhinus macrolepis eggs with sperm subjected to two freeze-thaw cycles. Theriogenology 69, 793-797.

Lahnsteiner F., Berger B., Weismann T., 2003, Effects of media, fertilization technique, extender, straw volume, and sperm to egg ratio on hatchability of cyprinid embryos, using cryopreserved semen. Theriogenology 60, 829-841.

Lahnsteiner F., Weismann T., Patzner R.A., 1992, Fine structural changes in spermatozoa of the frayling, Thymallus thymallus (Pisces: Teleostei), during routine cryopreservation. Aquaculture $103,73-84$.

Lin C., Zhang T., Rawson D.M., 2009, Cryopreservation of zebrafish (Danio rerio) blastomeres by controlled slow cooling. Cryoletters 30, 132-141.

Linhart O., Benesovsky J., 1991, Artificial insemination in asp (Aspius aspius L.). Anim. Sci. 36, 973-980.

Liu Q.H, Zhang S.C, Xiao Z.Z, Ding F.H, Yu D.D, Xu X.Z., 2007, Flow cytometry and ultrastructure of cryopreserved red seabream (Pagrus major) sperm. Theriogenology 67, 1168-1174.

Melo F.C.S.A, Godinho H.P., 2006, A protocol for cryopreservation of spermatozoa of the fish Brycon orthotaenia. Anim. Reprod. 3, 380-385.

Mongkonpunya K., Chairak N., Pupipat T., Tiersch T.R., 1995, Cryopreservation of Mekong giant catfish sperm. Asian Fish. Sci. 8, 211-221

Muchlisin Z.A., Muhammadar., 2002, Long-term cryopreservation of baung spermatozoa, Mystus nemurus: effect of various cryoprotectants on motility and fertility. Torani 12, 204-210.
Muchlisin Z.A., 2005, Current status of extenders and cryoprotectants on fish spermatozoa cryopreservation. Biodiversitas 6, 66-69.

Ohta H., Kawamura K., Unuma T., Takegoshi Y., 2001, Cryopreservation of the sperm of the Japanese bitterling. J. Fish Biol. 58, 670-681.

Oshima M., 1920, Notes on freshwater fishes of Formosa, with description of new genera and species. Proc. Acad. Nat. Sci. Phil. $122,120-135$.

Perchec-Poupard G., Gatti J.L., Jeulin C., Fierville F., Billard R., 1997, Effects of extracellular environment on the osmotic signal transduction involved in activation of motility of carp spermatozoa. J. Reprod. Fert. 110, 315-327.

Psenicka M., Rodina M., Nebesarova J., Linhar O., 2006, Ultrastructure of spermatozoa of tench Tinca tinca observed by means of scanning and transmission electron microscopy. Theriogenology 66, 1355-1363.

Suquet M., Dreanno C., Fauvel C., Cosson J., Billard R., 2000, Cryopreservation of sperm in marine fish. Aquac. Res. 31, 231-243.

Tian Y.S., Chen S.L., Ji X.S., Zhai J.M., Sun L.J., Chen C., Su P.Z., 2008, Cryopreservation of spotted halibut (Verasper variegates) sperm. Aquaculture 284, 268-271.

Tiersch T.R., Yang H., 2009, Current status of sperm cryopreservation in biomedical research fish models: zebrafish, medaka, and Xiphophorus. Comp. Biochem. Physiol. C Toxicol. Pharmacol. 149, 224-232.

Tsai S., Rawson D.M., Zhang T., 2008, Studies on cryoprotectant toxicityto early stage zebrafish (Danio rerio) ovarian follicle. Cryoletters 29, 477-483.

Van der Straten K.M., Leung L.K., Rossini R., Johnston S.D., 2006, Cryopreservation of spermatozoa of black marlin, Makaira indica (Teleostei: Istiophoridae) Cryoletters 27, 203-209.

Viveiros A.T.M., Lock E.J., Woelders H., Komen J., 2001, Influence of cooling rates and plunging temperatures in an interrupted slow-freezing procedure for semen of the African catfish Clarias gariepinus. Cryobiology 43, 276-287.

Watson P.F., 2000, The causes of reduced fertility with cryopreserved semen. Anim. Reprod. Sci. 60/61, 481-492.

Yao Z., Crim L.W., Richardson G.F., Emerson C.J., 2000, Motility, fertility and ultrastructural changes of ocean pout (Macrozoarces americanus) sperm after cryopreservation. Aquaculture 181, 361-375. 